\title{
Resistance to organic hydroperoxides requires ohr and ohrR genes in Sinorhizobium meliloti
}

\author{
Catherine Fontenelle, Carlos Blanco, Morgane Arrieta, Virginie Dufour and Annie Trautwetter
}

\begin{abstract}
Background: Sinorhizobium meliloti is a symbiotic nitrogen-fixing bacterium that elicits nodules on roots of host plants Medicago sativa. During nodule formation bacteria have to withstand oxygen radicals produced by the plant. Resistance to $\mathrm{H}_{2} \mathrm{O}_{2}$ and superoxides has been extensively studied in S. meliloti. In contrast resistance to organic peroxides has not been investigated while S. meliloti genome encodes putative organic peroxidases. Organic peroxides are produced by plants and are highly toxic. The resistance to these oxygen radicals has been studied in various bacteria but never in plant nodulating bacteria.

Results: In this study we report the characterisation of organic hydroperoxide resistance gene ohr and its regulator ohrR in S. meliloti. The inactivation of ohr affects resistance to cumene and ter-butyl hydroperoxides but not to hydrogen peroxide or menadione in vitro. The expression of ohr and ohrR genes is specifically induced by organic peroxides. OhrR binds to the intergenic region between the divergent genes ohr and ohrR. Two binding sites were characterised. Binding to the operator is prevented by OhrR oxidation that promotes OhrR dimerisation. The inactivation of ohr did not affect symbiosis and nitrogen fixation, suggesting that redundant enzymatic activity exists in this strain. Both ohr and ohrR are expressed in nodules suggesting that they play a role during nitrogen fixation.

Conclusions: This report demonstrates the significant role Ohr and OhrR proteins play in bacterial stress resistance against organic peroxides in S. meliloti. The ohr and ohrR genes are expressed in nodule-inhabiting bacteroids suggesting a role during nodulation.
\end{abstract}

\section{Background}

Sinorhizobium meliloti is a soil bacterium that must survive and proliferate in various adverse conditions. $S$. meliloti is also able to establish a symbiotic partnership with Medicago sativa leading to the formation of nodules. In nodules, the bacterium differentiates in bacteroids and fixes atmospheric nitrogen. Within the soil and during nodulation, S. meliloti copes with various stresses imposed by the environment [1] or by plant responses to bacterial invasion [2,3]. While nodulation is a close association between plant and S. meliloti, bacteria are initially recognised as intruders and induce an oxidative burst [4].

An increased production of reactive oxygen species (ROS), including superoxides, $\mathrm{H}_{2} \mathrm{O}_{2}$ and organic hydroperoxides is an important component of plant

\footnotetext{
* Correspondence: annie.trautwetter@univ-rennes1.fr
UMR CNRS 6026, DUALS. Université de Rennes I, Campus de Beaulieu, Av. du

* Correspondence: annie.trautwetter@univ-rennes1.fr
UMR CNRS 6026, DUALS. Université de Rennes I, Campus de Beaulieu, Av. du Général Leclerc, 35042 Rennes, France
} General Leclerc, 35042 Rennes, France

()

defences [5]. In free living bacteria oxidative stress results from aerobic metabolism [6], ROS are produced as a result of the incomplete reduction of molecular oxygen [7]. Hence, both in free living and symbiotic stages, S. meliloti produces enzymes to detoxify ROS. Only those that detoxify superoxide anion and $\mathrm{H}_{2} \mathrm{O}_{2}$ have been studied extensively Superoxides are detoxified by two superoxide dismutases [8,9], $\mathrm{H}_{2} \mathrm{O}_{2}$ by three catalases (KatA, KatB and $\mathrm{KatC}$ ) [10] and a chloroperoxidase (Cpo) [11]. Little is known about resistance to organic peroxides (OHPs) in S. meliloti. OHPs are generated as part of the active defence response of plants $[12,13]$. OHPs are highly toxic. They participate in free radical reactions that generate more toxic ROS by reacting with membranes and other macromolecules [14]. Thus, detoxification of OHPs is important for bacterial survival and proliferation.

Bacteria possess two systems to protect themselves against organic peroxide toxicity. Peroxiredoxines have 
been shown to be the main peroxide detoxification enzymes in eukaryotes and bacteria $[15,16]$. Alkyl hydroperoxidase reductase (Ahp) constitutes the best characterised member of peroxiredoxin family $[17,18]$. This enzyme is composed of a reductase subunit and a catalytic subunit reducing organic peroxides to alcohols [18]. The second class of OHP detoxification enzymes (OsmC/Ohr family) is only found in bacteria [19]. The Ohr (Organic Hydroperoxide Resistance) protein first discovered in Xanthomonas campestris [20], and OsmC (Osmotically inducible protein) [21] are hydroperoxide peroxidases catalysing the reduction of hydroperoxides into their corresponding alcohols [22,23]. Both Ohr and OsmC are structurally and functionally homologous proteins. They are homodimeric with the active sites on either side of the molecule $[23,24]$. Their active sites contain two highly conserved cysteines which are involved in peroxide metabolism [24,25]. Despite this conservation of the proteins, OsmC and Ohr display different patterns of regulation and distinct physiological functions [23]. The expression of ohr is specifically induced by organic peroxides and not by ethanol and osmotic stress [19], while osmC is not induced by organic peroxides; instead it is induced by ethanol and osmotic stress and controlled by multiple general stress responsive regulators [15]. The inactivation of ohr, but not $\operatorname{osm} C$, reduces the resistance only against organic peroxides, and not to other oxidants [20].

The expression of $o h r$ is regulated by the organic peroxide-inducible transcription repressor OhrR, a member of MarR family. Structural data are available for OhrR of Bacillus subtilis [26] and OhrR of X. campestris [27]. OhR functions as a dimeric repressor that binds the ohr promoter region in the absence of organic peroxides. Derepression results from the oxidation of a highly conserved active site cysteine that resides near the $\mathrm{NH}_{2}$ terminus of the protein [28]. B. subtilis OhrR contains only one cysteine; its oxidation leads to the formation of a mixed disulfide with a low molecular weight thiol, a cyclic sulfenamide, or overoxidation to sulfinic or sulfonic acids [29]. In other bacteria, like X. campestris, OhrR contains a second cysteine located on the $\mathrm{COOH}$ extremity of the OhrR protein (C127 for X. campestris). Oxidation of the protein initiates by the formation of a sulphenic derivative of the reactive cysteine (C22) followed by the formation of a disulfide bond with $\mathrm{C} 127$ of the other OhrR subunit [30]. While ohr homologues are widely distributed in bacterial genomes [19], the role of $o h r$ and $o h r R$ was only studied in a few number of bacteria: X. campestris, B. subtilis, Agrobacterium tumefasciens, Pseudomonas aeruginosa and Streptomyces coelicolor [20,31-35].

In many bacteria, peroxide stress was studied only via $\mathrm{H}_{2} \mathrm{O}_{2}$ stress. In S. meliloti, $\mathrm{H}_{2} \mathrm{O}_{2}$ resistance has been extensively studied $[8,10,11]$ while OHP resistance is poorly understood. This study aims at evaluating the role of $o h r$ and ohrR genes on OHP resistance in $S$. meliloti. The analysis of the biochemical properties of $o h r$ and ohrR mutants and the expression pattern suggests that this system should play an important role in sensing and protection of $S$. meliloti from OHPs.

\section{Results}

Identification of Ohr and OhrR homologues in S. meliloti Blast search of $S$. meliloti genome for homologues of $X$. campestris Ohr protein revealed two paralogues, SMa2389 and SMc00040, showing 52 and 57\% identity respectively with $\mathrm{Ohr}$ of $X$. campestris. They possess conserved active site cysteines of $\mathrm{Ohr} / \mathrm{OsmC}$ proteins [19]. SMa2389 is annotated as OsmC. SMc00040 has been shown to be induced by peroxide stress [11]; it is divergently located from a gene encoding a MarR family regulator that has 49 and $45 \%$ identity with the OhrR regulatory protein of $X$. campestris and B. subtilis respectively. SMc01945 has been previously published as OhrR like repressor since it presents $40 \%$ identity with OhrR of $X$. campestris [11]; the adjacent gene cpo (SMc01944) has been shown to encode a secreted peroxidase.

Co-localisation on the genome of ohr and ohrR was found in all bacteria in which these genes were investigated $[20,31,36]$, suggesting that SMc00040 and SMc00098 encodes respectively Ohr and OhrR proteins.

\section{ohr mutant growth is inhibited by organic peroxides}

In order to investigate the role of ohr (SMc00040) and ohrR (SMc00098) in oxidative stress defence, S. meliloti strains with an ohrR deletion or carrying an insertion in $o h r$ were constructed. The ability of these mutants to resist exposure to oxidants was evaluated; neither of the two had any growth defect when grown aerobically in complete medium LB or in minimal medium GAS. Moreover they possessed the same plating efficiency as wild type strain.

The influence of organic peroxides on growth of wild type, ohr and ohrR strains was analysed by adding increasing amounts of t-butyl hydroperoxide (tBOOH) and cumene hydroperoxide $(\mathrm{CuOOH})$ to $\mathrm{LB}$ medium and determining the maximal $\mathrm{OD}_{570} \mathrm{~nm}$ reached by the cultures. A concentration of $2 \mathrm{mM} \mathrm{tBOOH}$ abolished the growth of ohr mutant while the growth yield of $o h r R$ and parental strains was unaffected. Similarly 0.5 $\mathrm{mM}$ of $\mathrm{CuOOH}$ abolished growth of ohr strain but did not affect growth yield of ohrR and parental strains.

Disk diffusion assays were used to determine if $o h r$ and $o h r R$ mutations affected resistance to ROS. The $o h r$ mutant was less resistant than its parental strain when challenged with organic peroxides as shown by the 
zones of growth inhibition: $4.1 \pm 0.2 \mathrm{~cm}$ for $\mathrm{CuOOH}$ and $3.1 \pm 0.1 \mathrm{~cm}$ for $\mathrm{tBOOH}$ versus to $2.3 \pm 0.2$ and 2.5 $\pm 0.3 \mathrm{~cm}$ for wild type strain. In contrast, ohrR mutation did not affect the resistance of $S$. meliloti against $\mathrm{tBOOH}$ and $\mathrm{CuOOH}$ since inhibition zones were not significantly ( $\mathrm{p}$ value $\leq 0.01$ ) different from those of wild type strain (Figure 1). The ohr-ohrR mutant behaved identically to the ohr mutant (Figure 1).

In other experiments, ohr and ohrR mutants were complemented by the moderate copy number plasmid pBBR1-MCS2 bearing wild type alleles of ohr (pBBohr) or ohrR (pBBohrR). The empty vector did not affect the resistance of wild type or mutants against $\mathrm{tBOOH}$ and $\mathrm{CuOOH}$. Plasmid vector carrying ohrR $R^{+}$allele also did not affect the resistance to OHPs of these three strains. In contrast the introduction of $\mathrm{pBBohr}$ in ohr mutant dramatically improved resistance to both $\mathrm{tBOOH}$ and $\mathrm{CuOOH}$ (Figure 1). These results showed that Ohr is important in the defence against organic peroxides in $S$. meliloti.

In comparison with parental strain, ohr and $o h r R$ mutants were not significantly affected in resistance to $\mathrm{H}_{2} \mathrm{O}_{2}$ and menadione; inhibition zones were nearly identical for the three strains. No alteration of this resistance was observed after complementation of the mutations with pBBohr or pBBohrR. This result agrees with the role of Ohr in other organisms and its specificity for organic peroxide resistance.

\section{Regulation of ohr and ohrR genes}

The transcriptional activity of $o h r$ and $o h r R$ genes was assayed in strain R7.16 carrying ohr::lacZ and ohrR::uidA transcriptional fusions in tandem with wild type copies of $o h r$ and ohrR genes.

The expression of these fusions was analysed in LB medium and in the minimal medium GAS. No difference was observed between both media. The expression of ohr::lacZ and ohrR::uidA was followed throughout growth till the late stationary growth phase. The expression of these two genes remained constant; no variation was observed after growth arrest. Adding $\mathrm{NaCl}$ to the medium during exponential growth or during stationary growth phase did not affect ohr or ohrR expression (data not shown). Such a result is expected for Ohr and clearly differentiates it from OsmC proteins that are induced by $\mathrm{NaCl}[15]$.

The influence of peroxides was analysed by introducing into the medium a concentration of peroxide that did not affect the development of exponentially growing cells. Expression of ohr was induced 4-fold in the presence of $1.6 \mathrm{mM} \mathrm{tBOOH}$, a 7 -fold induction was observed with $0.25 \mathrm{mM} \mathrm{CuOOH}$. The addition of $10 \mathrm{mM} \mathrm{H}_{2} \mathrm{O}_{2}$ resulted in a 2-fold induction of $o h r$ (Figure 2).

Induction of $o h r R$ was also observed when cultures were exposed to $\mathrm{tBOOH}$ and $\mathrm{CuOOH}$, induction ratios were lower than those observed for $o h r$ gene. In contrast $\mathrm{H}_{2} \mathrm{O}_{2}$ did not affect ohrR expression (Figure 2).

\section{OhrR regulates ohr expression}

A plasmid bearing ohr::lacZ transcriptional fusion (pE1541) was introduced into the ohrR mutant and the parental strain. The expression of the fusion was analysed in LB medium in the absence of organic peroxides and $1 \mathrm{~h}$ after $0.25 \mathrm{mM} \mathrm{CuOOH}$ addition. In the absence of peroxide, the expression of ohr::lacZ fusion was greater in the ohrR mutant than in the wild type strain $(18.5 \pm 1.3$ and $9.6 \pm 0.7 \mu \mathrm{mol}$ of substrate hydrolysed $\mathrm{min}^{-1} \mathrm{mg}$ of protein ${ }^{-1}$ respectively). After $\mathrm{CuOOH}$ addition, the expression of ohr::lacZ was similar in ohrR mutant and parental strain $(16.7 \pm 1.4$ and $17.5 \pm 1.5$ $\mu \mathrm{mol}$ of substrate hydrolysed $\mathrm{min}^{-1} \mathrm{mg}$ of protein ${ }^{-1}$ respectively). These results are in accordance with repression of ohr promoter by the OhrR regulator.

\section{OhrR binds to ohr-ohrR intergenic region}

The binding of OhrR to ohr-ohrR intergenic region was analysed by gel mobility shift assay. In a first attempt, a 113 bp DNA fragment encompassing the entire ohr-

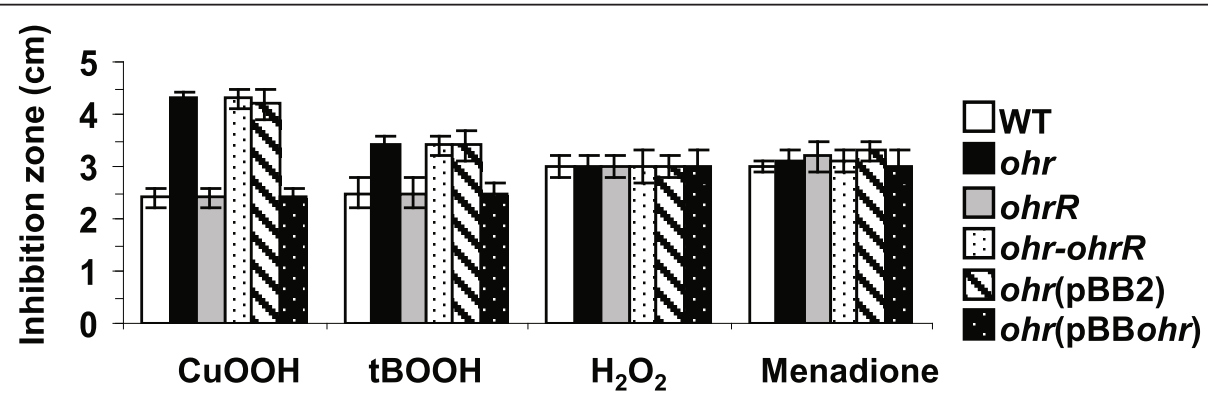

Figure 1 Resistance of the ohr and ohrR mutants to ROS. The resistance of wild type (WT), ohr, ohrR, ohr-ohrR mutants and ohr mutant complemented by plasmids pBBR1-MSC2 [ohr (pBB2)] and pBBohr [ohr (pBBohr)] was analysed by disk diffusion assay on LB plates as described in methods. The data correspond to five independent experiments; standard deviation is indicated (bars). 


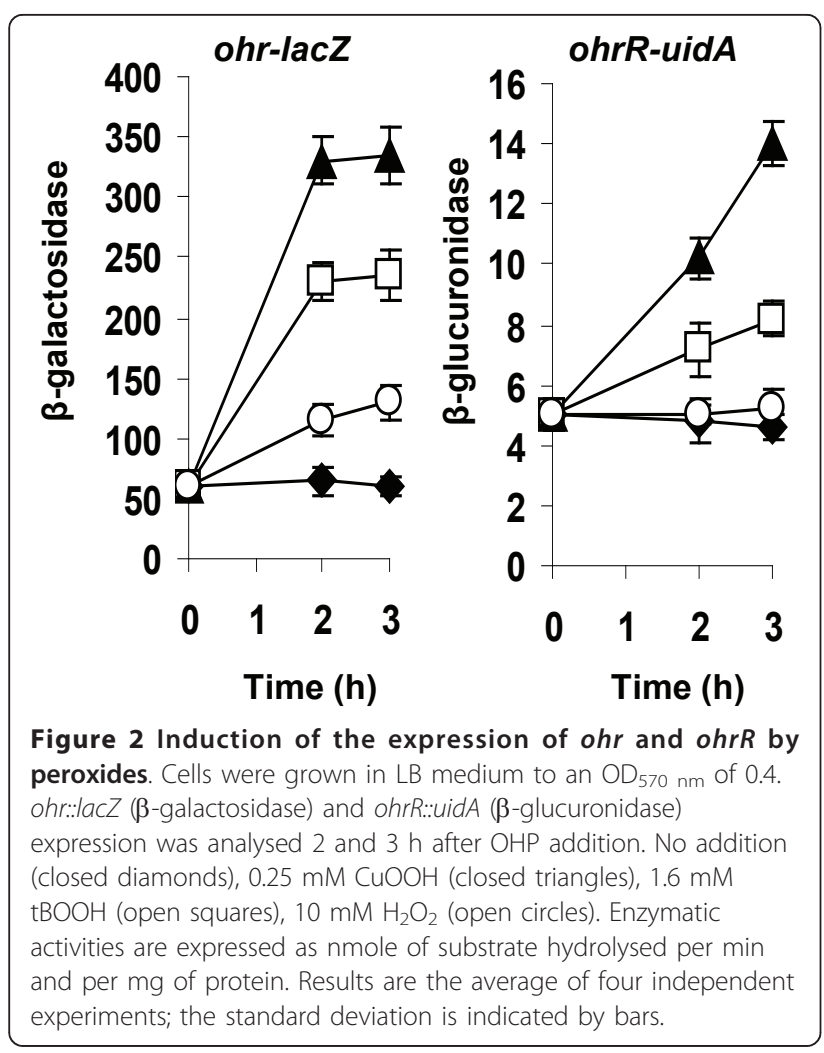

ohrR intergenic region and ended at the initiation codons of $o h r$ and $o h r R$, was used as a probe (Figure 3A). Two retarded bands were observed in the presence of OhrR (Figure 3B). The intergenic region between SMb20903 and SMb20964 (this latter gene encoding the putative AhpC protein of $S$. meliloti) was used as a negative control. No specific binding of OhrR protein to this DNA fragment was observed (data not shown).

We took advantage of restriction sites located within the ohr-ohrR intergenic region to define further OhrR binding site. ApoI cleaved once this fragment giving a $17 \mathrm{bp}$ and a $96 \mathrm{bp}$ fragment. In the presence of OhrR protein the longer fragment produced two shifted bands (Figure 3). Two HpaII sites are located within ohr-ohrR intergenic region; HpaII cleavage produced three fragments of 26,29 and $58 \mathrm{bp}$. In the presence of OhrR, the intensity of the 58 bp fragment decreased and two retarded bands were observed (Figure 3B). Thus OhrR binding sites are located within the 58 bp HpaII fragment. None of the DNA fragments generated by Bss HII (54 and $59 \mathrm{bp}$ ) or MseI (47, 50 and $16 \mathrm{bp}$, the last not detected on the gel) were shifted in the presence of OhrR (Figure 3B). The unique Bss HII and both MseI sites are located within the $58 \mathrm{bp} H$ paII region, which suggests that OhrR binding site is located within the 16 bp MseI fragment or overlaps its extremities and overlaps the BssHII site.
Two imperfect palindroms (Figure 3A) are located within the $58 \mathrm{bp} \mathrm{HpaII}$ region. Moreover MseI and BssHII sites overlap these motifs. Motif 1 (GCAAATTAATTTTG) and motif 2 (GCAAATTGCTTTGC) look like the OhrR binding site GCAATT-AATTCG found in other bacteria [31,34,36,37]. Motif 1 and motif 2 are adjacent as observed for OhrR binding sites of $B$. subtilis [36], A. tumefaciens [31], S. coelicolor [34] and X. campestris [37].

To further analyse OhrR binding, 60 bp DNA fragments containing in their centre $17 \mathrm{nt}$ corresponding either to motif 1 or motif 2 were synthesised. The OhrR protein was found to bind to both fragments. Mutations were introduced in motif 1 to confirm the importance of this sequence. The modification of GC to AA or AAA to CCC in one half of the palindrome abolishes the binding of OhrR to the DNA fragments (Figure3C).

\section{Modulation of OhrR activity by oxidation}

S. meliloti OhrR protein contains two cysteine residues conserved at the same position than in OhrR of $X$. Campestris, allowing the possibility to form inter-subunit disulfide bonds upon oxidation.

Purified OhrR was treated with $\mathrm{CuOOH}, \mathrm{H}_{2} \mathrm{O}_{2}$ or DTT and the products were analysed by non reducing SDS-PAGE (Figure 4A). In the presence of DTT, $S$. meliloti OhrR protein migrated as a band of an apparent MW of $15 \mathrm{kDa}$ (the calculated molecular mass being $17.5 \mathrm{kDa}$ ). Incubation of the protein with $\mathrm{CuOOH}$ or $\mathrm{H}_{2} \mathrm{O}_{2}$ led to the formation of a band of $30 \mathrm{kDa}$ corresponding to the dimeric form. The formation of the dimer was reversed by an excess of DTT. Thus, as observed in X. campestris [30], the oxidation of OhrR induces a reversible bonding between the two subunits of the protein (Figure 4A).

Binding of OhrR to ohr-ohrR intergenic region was suppressed when $10 \mathrm{mM} \mathrm{H}_{2} \mathrm{O}_{2}$ was added to the binding mixture. Binding was recovered after addition of an excess of DTT. Thus only the reduced form of OhrR was able to bind DNA (Figure 4B).

\section{ohr strain forms fix ${ }^{+}$nodules in alfalfa}

The sensitivity of S. meliloti ohr mutants to OHPs is potentially relevant to symbiosis since legume root cells respond to rhizobial infection with an enhanced production of ROS $[4,38]$. To test the effect of ohr mutation on nodulation and nitrogen fixation, one week old seedlings of Medicago sativa were inoculated with either the S. meliloti ohr mutant or the parental strain. Plants were grown in nitrogen-deprived medium. Five weeks after the inoculation, plants were visually screened for nodulation by observing the root system. A highly efficient nodulation was observed on plants inoculated with either ohr or parental strains. No significant difference between dry weights 
A

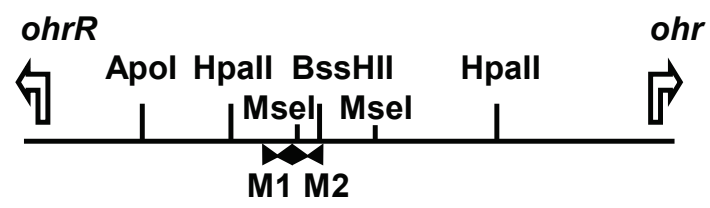

B

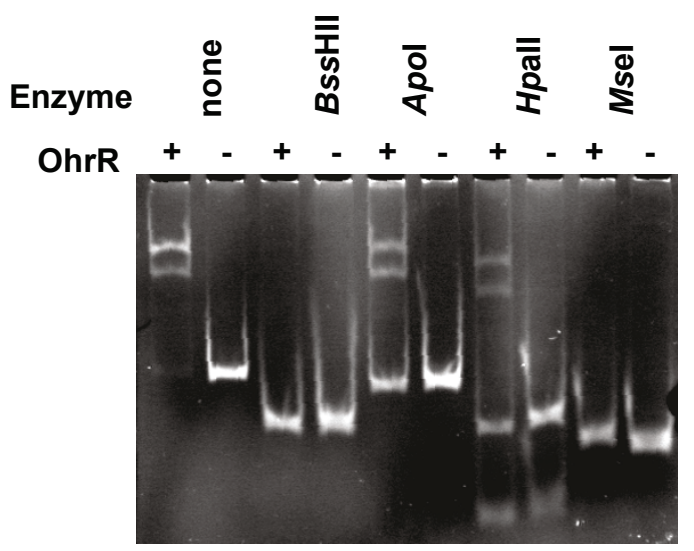

\section{C}

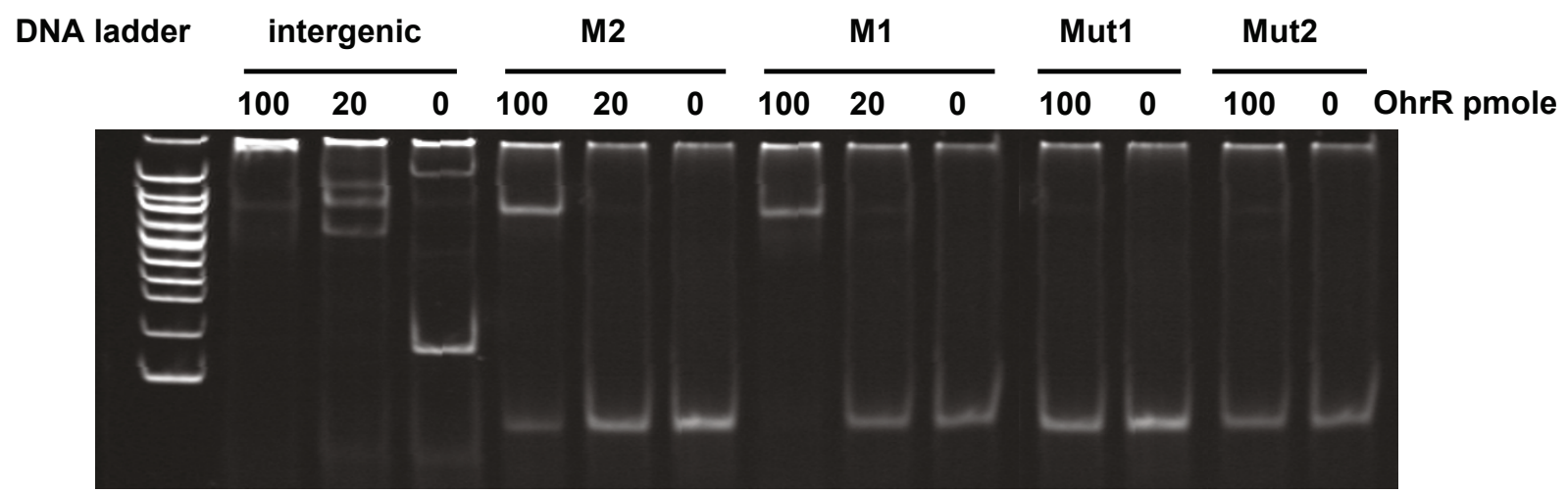

M1 GGGGGGGAAGCTAGTCACCGCAAATTAATTTGCGATACTAGAGAGATGCATATGGGGGG

M2 GGGGGGGAAGCTAGTCACCGCAAATTGCTTTGCCGATACTAGAGAGATGCATATGGGGGG

Mut1 GGGGGGGAAGCTAGTCACCAAAAATTAATTTGCGATACTAGAGAGATGCATATGGGGGG

Mut2 GGgGGGGAAGCTAGTCACCGCCССтAAтTTTGCGATACTAGAGAGATGCATATGGGGGG

Figure 3 Localisation of OhrR binding sites. A-Restriction map of the $113 \mathrm{bp}$ ohr-ohrR intergenic region used in gel mobility shift assay. The location of the initiator codon and translation direction of ohr and ohrR is indicated by a white arrow. The position of the two palindromic binding motifs Motif 1 (M1) and Motif 2 (M2) is indicated by black arrows. B-Gel mobility shift assay of the ohr-ohrR intergenic region and of its restriction fragments produced by BssHII, Apol, Hpall or Msel. DNA (20 pmoles) was incubated in the presence (+) or in the absence (-) of 20 pmoles of OhrR. C-Binding of OhrR to Motif 1 and Motif 2 sequences. Gel shift assay of the intergenic region and the 60 bp double strand sequences containing at their centre the genuine 17 nt corresponding to Motif 1 and Motif 2, or mutated Motif 1 with AA in place of GC (Mut1 fragment) and CCC in place of AAA (Mut2 fragment). DNA (20 pmoles) was incubated with the indicated amount of OhrR in the presence of $1 \mathrm{mM}$ DTT.

of plant shoots was observed. The inoculated plants had green leaves and comparable number of nodules, whereas the non-inoculated control plants were smaller, with yellow leaves and significantly lower dry weight. Nodules from plants inoculated with the ohr mutant were crushed and the bacteria recovered by plating on MSY plates before assayed for gentamycine resistance and OHP sensitivity. All the randomly selected colonies that were analysed were able to grow on gentamycine-containing plates and behaved like the original ohr mutant. Thus $\mathrm{N}_{2}$-fixing nodules formed on alfalfa were due to infection by the ohr mutant and not by revertants. 


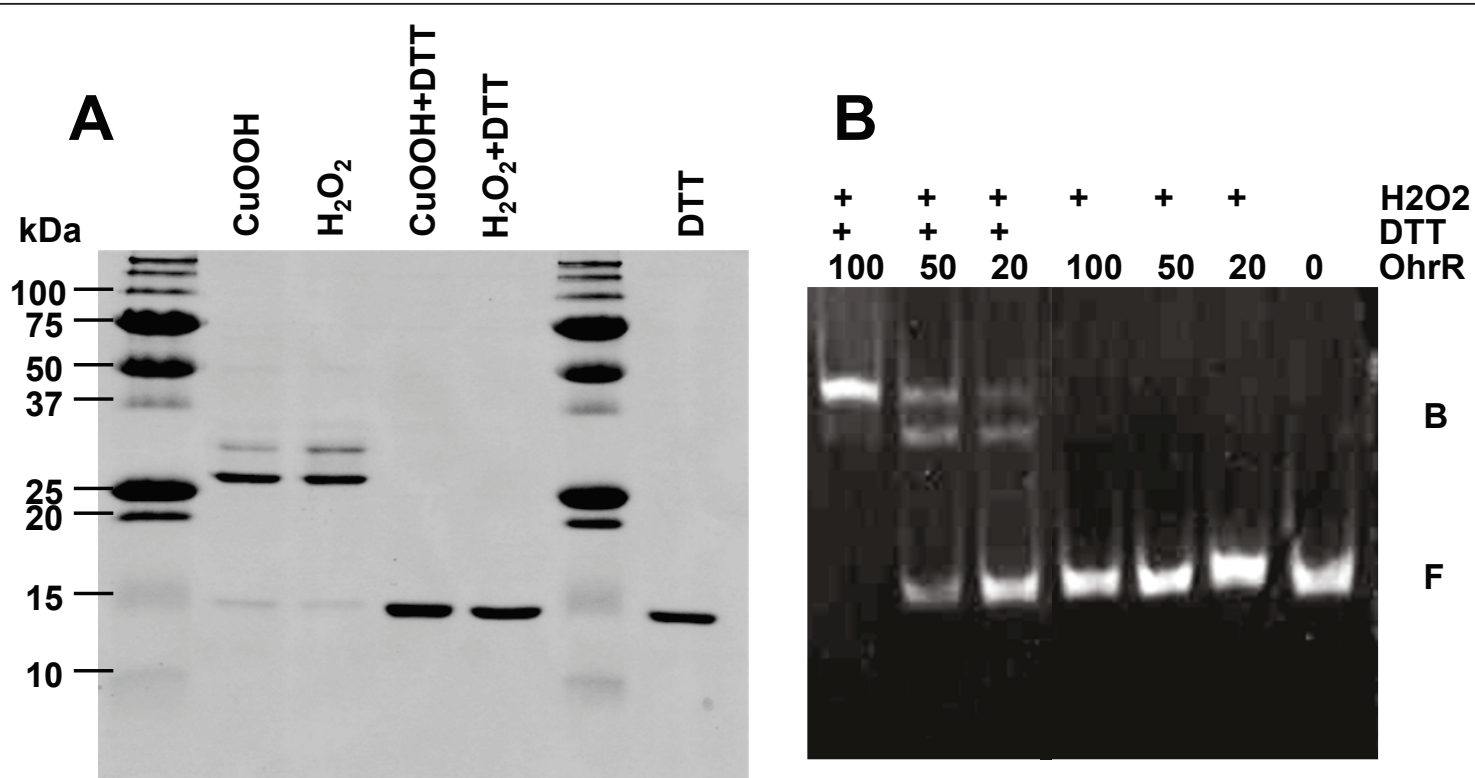

Figure 4 Oxidation promotes OhrR dimerisation and inactivation. (A) OhrR purified protein (20 nmoles) was incubated for 15 min with $\mathrm{CuOOH}(0.55 \mathrm{nM})$ or $\mathrm{H}_{2} \mathrm{O}_{2}(0.5 \mathrm{nM})$ and then, when indicated, added with $0.5 \mathrm{mM}$ DTT and incubated for another 15 min. (B) The DNA fragment (20 pmoles) corresponding to ohr-ohrR intergenic region was incubated with purified OhrR protein (20, 50 or 100 pmoles) in the presence of $0.5 \mathrm{nM} \mathrm{H}_{2} \mathrm{O}_{2}$ and in the absence or in the presence of $0.5 \mathrm{mM}$ DTT.

In order to analyse ohr and ohrR expression in planta, $\beta$-galactosidase and $\beta$-glucuronidase activity were visualised by light microscopy on entire and sections of nodules from R7.16 (ohr-lacZ, ohrR-uidA, ohr ${ }^{+}$, ohrR ${ }^{+}$) infected plants (Figure 5). No staining was observed in root hairs or infection threads. Nodule staining co localises with pink coloration of leghemoglobin, corresponding to nitrogen fixation zone (data not shown). Thus, in spite of the absence of a nodulation defect of ohr strain,

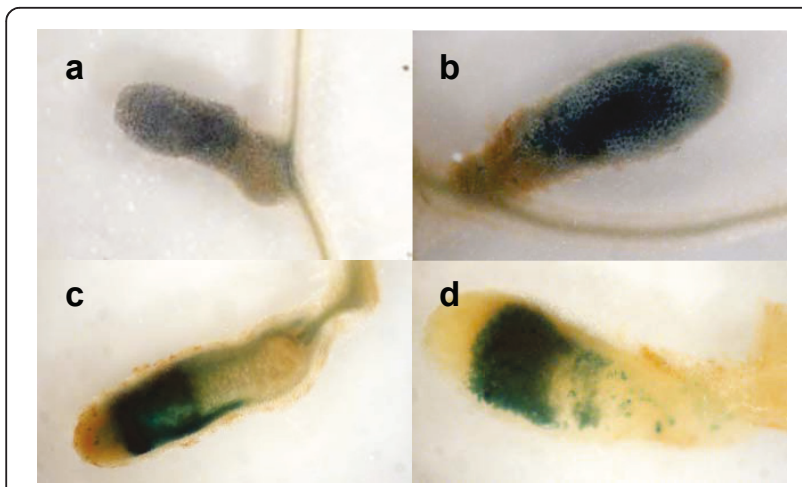

Figure 5 Expression of $o h r$ and ohrR in planta. Nodules were fixed and stained with 5-bromo-4-chloro-3-indolyl-beta-Dgalactopyranoside ( $\beta$-galactosidase detection) (a,c) or 5-bromo-4chloro-3-indolyl-beta-D-glucuronate ( $\beta$-glucuronidase detection) (b, d) and visualised by light microscopy. ( $a$, b) whole nodules, ( $c$, d) thin sections of stained nodules. The images are representative of 30 nodules analysed. both $o h r$ and $o h r R$ genes were expressed during nodulation. This result is in accordance with the detection of Ohr protein in nodules in proteomic studies [39].

\section{Discussion}

In this study, we analysed the role of ohr and ohrR genes in S. meliloti. As many bacteria, S. meliloti must survive oxidative stress generated by the environment or during symbiosis. ROS attack of cellular membranes generates a cascade of radicals leading to the formation of OHPs [7]. Moreover, OHPs are produced by plants as part of the defence response against bacteria $[12,13]$. Organic peroxides are potent effectors of $o h r$ system in bacteria [40].

Ohr is not essential for nodulation. Bacteria containing ohr mutations formed effective nodules, suggesting that $S$. meliloti does not undergo OHP stress during nodulation or that other enzymes detoxify OHP like AhpC (a putative ahpC gene: SMb20964 was annotated) as described in $X$. campestris [41]. The redundancy of enzymatic activities was also described for catalases in $S$. meliloti; only strains affected at least for two catalases are compromised in symbiosis [10]. Both ohr and ohrR are specifically induced by OHPs and are expressed in nodules but no OHP detection was reported, so we could not exclude the existence of other compounds inducing ohr and ohrR.

Like in many bacteria, $o h r$ is located at the immediate vicinity of its regulator: ohrR (SMc00098). This ORF 
encodes a regulatory protein of the MarR family as all known OhrR regulators. The regulator OhrR is a dimeric regulatory protein that senses organic peroxides. Two families of OhrR proteins exist; they are exemplified by OhrR of B. subtilis and OhrR of X. campestris. These two proteins share $40 \%$ amino acid identity and are structurally similar [26,27]. Nevertheless, they differ in their peroxide sensing mechanisms. The B. subtilis OhrR protein family contains only one cysteine residue. Depending on the oxidant, OhrR gives reversible oxidised derivatives or functions as a sacrificial regulator [42]. The $X$. campestris OhrR possesses another important cysteine (C127). The initially oxidized cysteine (C22) forms intersubunits disulfide bonds with the residue $\mathrm{C} 127$ on the second subunit of the dimer, leading to reversible inactivation of the protein [30]. The introduction of a second cysteine into B. subtilis OhrR (position 120 to 124) allows B. subtilis OhrR to function as $X$. campestris $\mathrm{OhrR}$, protecting the protein against irreversible oxidation in presence of strong oxidants [43]. Comparison of S. meliloti OhrR protein with that of $B$. subtilis and $X$. campestris shows that $S$. meliloti protein keeps similar amino acid identity with both proteins (45 and $49 \%$ respectively). S. meliloti possesses two cysteines at the same position than OhrR of $X$. Campestris. We observed that protein oxidation led to the formation of a dimer and loss of DNA binding, these phenomena are reversed by DTT in vitro. Thus $S$. meliloti OhrR oxidation mechanism is similar to that described for OhrR of $X$. campestris.

The expression of ohr and ohrR was assayed at the transcriptional level. Their expression was constant throughout growth and no induction during stationary growth phase was observed. Similarly, osmotic stress did not induce ohr or ohrR expression. These observations match with the expression of these genes in $X$. campestris, A. tumefasciens, B. subtilis, P. aeruginosa and $S$. coelicolor $[20,31,32,34,44]$. As previously observed in these bacteria, ohr and ohrR genes of $S$. meliloti were induced by $\mathrm{tBOOH}$ and $\mathrm{CuOOH} . \mathrm{H}_{2} \mathrm{O}_{2}$ was a poor inducer of ohr gene in S. meliloti. Induction of $o h r$ by $\mathrm{H}_{2} \mathrm{O}_{2}$ in other bacteria is contradictory. Western analysis and gene fusion assays showed that ohr is not induced by $\mathrm{H}_{2} \mathrm{O}_{2}$ in A. tumefasciens, B. subtilis, $P$. aeruginosa and $S$. coelicolor $[31,33,34,36]$ and only $X$. campestris ohr is slightly induced by $\mathrm{H}_{2} \mathrm{O}_{2}$ [20]. Transcriptomic studies of $\mathrm{H}_{2} \mathrm{O}_{2}$ stress response in B. subtilis [32] and P. aeruginosa [44] showed in contrast an ohr induction.

Induction of ohr requires the oxidation of OhrR. We observed that $S$. meliloti $\mathrm{OhrR}$ is oxidized by $\mathrm{H}_{2} \mathrm{O}_{2}$ in vitro and did not bind to the operator when incubated with $\mathrm{H}_{2} \mathrm{O}_{2}$. Nevertheless, $\mathrm{H}_{2} \mathrm{O}_{2}$ is a poor inducer of $o h r$ in vivo and is not an inducer of ohrR expression. $\mathrm{H}_{2} \mathrm{O}_{2}$ also causes a loss of B. subtilis OhrR binding to ohrA promoter in vitro while in vivo derepression of ohrA upon exposure to $\mathrm{H}_{2} \mathrm{O}_{2}$ was not observed $[28,36]$. The role of $\mathrm{H}_{2} \mathrm{O}_{2}$ in alfalfa during symbiosis is not restricted to plant defence against bacteria. It is also important for symbiotic process [45]. $\mathrm{H}_{2} \mathrm{O}_{2}$ is necessary for cell wall formation and infection thread rigidity [4]. Production of $\mathrm{H}_{2} \mathrm{O}_{2}$ was detected in root hairs, infection threads, infection and senescence zones but not in fixing zone [46]. The expression of $o h r$ and $o h r R$ was detected only in nitrogen fixing zone, thus they are not expressed constitutively and they are not induced by $\mathrm{H}_{2} \mathrm{O}_{2}$ in planta. These data suggest that organic peroxides are produced in nodules so that Ohr protein plays a role during nitrogen fixation.

\section{Conclusions}

Resistance to organic hydroperoxides has not been previously analysed in S. meliloti. We have demonstrated that Ohr protein is essential for S. meliloti to survive organic peroxide stress. The expression of $o h r$ and $o h r R$ genes in nodules suggests that the Ohr protein participates in organic peroxides detoxification within the nodule.

\section{Methods}

\section{Bacterial strains, plasmids, and culture conditions}

The bacterial strains used in this study are detailed in Table 1. S. meliloti strains were grown aerobically at $30^{\circ}$ $\mathrm{C}$ in the complex medium LB [47] to an optical density at $570 \mathrm{~nm}\left(\mathrm{OD}_{570}\right)$ of 1.5 to 1.8 ; they were then inoculated in minimal galactose aspartate salts medium (GAS) [48] or LB medium at an $\mathrm{OD}_{570 \mathrm{~nm}}$ of 0.1. E. coli strains were grown aerobically in LB medium at $37^{\circ} \mathrm{C}$. For the selection of $E$. coli strains, ampicillin was added at 50 or $100 \mu \mathrm{g} \mathrm{ml}^{-1}$, tetracycline at $10 \mu \mathrm{g} / \mathrm{ml}$, chloramphenicol at $25 \mu \mathrm{g} / \mathrm{ml}$, and neomycin or kanamycin at $50 \mu \mathrm{g} / \mathrm{ml}$. For the selection of $S$. meliloti strains, streptomycin was used at $100 \mu \mathrm{g} / \mathrm{ml}$, tetracycline at $5 \mu \mathrm{g} / \mathrm{ml}$, and neomycin at $25 \mu \mathrm{g} / \mathrm{ml}$.

\section{DNA manipulations and mutant constructions}

Standard protocols were used for DNA manipulations [49].

\section{$\beta$-glucuronidase and $\beta$-galactosidase assays}

$\beta$-glucuronidase and $\beta$-galactosidase assays were carried out as described $[47,50]$. Specific activities are expressed as nanomoles of ortho-nitrophenol liberated per minute per milligram of protein. Protein concentration was determined by the method of Bradford with bovine serum albumin as a standard. Results are the mean of at least three independent experiments, and the standard deviation was less than $10 \%$. 
Table 1 Bacterial strains and plasmids

\begin{tabular}{|c|c|c|}
\hline Strains & genotype & origin \\
\hline \multicolumn{3}{|l|}{ E. coli } \\
\hline $\mathrm{DH} 5 \alpha$ & endA-1 hsdR-17 supE-44 thi-1 recA-1 gyrA relA-1 $\triangle($ lacZYA-argG)U169 deoR & {$[57]$} \\
\hline MT616 & MM294 pRK600 $\mathrm{Cm}^{\mathrm{R}}$ & {$[58]$} \\
\hline BL21(DE3) & 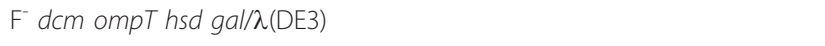 & {$[59]$} \\
\hline \multicolumn{3}{|c|}{ Sinorhizobium meliloti } \\
\hline Rm1021 & SU47 Sm $\mathrm{Sm}^{\mathrm{R}}$ & {$[60]$} \\
\hline R6.48 & Rm1021,ohrR::Gm ${ }^{R}$ & This study \\
\hline R7.15 & 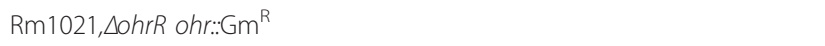 & This study \\
\hline R7.16 & Rm1021,ohr ${ }^{+}$ohrR ${ }^{+}$ohr::lacZ ohrR::uidA & This study \\
\hline R8.39 & Rm1021,ohr::Gm ${ }^{R}$ & This study \\
\hline \multicolumn{3}{|l|}{ Plasmids } \\
\hline PGEMT & pUC derivative cloning vector, $A_{m p}{ }^{R}$ & Promega \\
\hline pGEMTeasy & pUC derivative cloning vector, $\mathrm{Amp}^{\mathrm{R}}$ & Promega \\
\hline pET22b+ & expression vector, $A m p^{R}$ & Novagen \\
\hline pK18mobsacB & mobilisable pUC derivative, $s a c B \mathrm{Neo}^{\mathrm{R}}$ & {$[51]$} \\
\hline pBBR1-MCS2 & broad host range replicating mobilisable vector, $\mathrm{Neo}^{\mathrm{R}}$ & {$[61]$} \\
\hline pBBR1-MCS5 & broad host range replicating mobilisable vector, $\mathrm{Gm}^{\mathrm{R}}$ & {$[61]$} \\
\hline pTH1505 & $\mathrm{Gm}^{\mathrm{R}}$, gfp, lacZ, uidA, rfp fusion vector & {$[54]$} \\
\hline p34SGm & ori ColEl Amp ${ }^{R} \mathrm{Gm}^{R}$ cassette & [52] \\
\hline pD3001 & pK18mobsacB (Xbal-Pstl)/ohrR downstream region (Xbal-Nsil) & this study \\
\hline pD3083 & pGEMTeasy/ ohrR upstream region & This study \\
\hline pD4116 & pK18mobsacB $\triangle$ ohrR & This study \\
\hline pD4244 & pK18mobsacB $\triangle$ ohrR::Gm ${ }^{R}$ & This study \\
\hline pD5333 & pK18mobsacB $\triangle$ ohrR ohr::Gm ${ }^{R}$ & This study \\
\hline pD5455 & pTH1505 ohr:./acZ, ohrR::uidA & This study \\
\hline pD8657 & pK18mobsacB ohr::Gm ${ }^{R}$ & This study \\
\hline pBBohr & pBBRI-MCS2 ohr ${ }^{+}$ & This study \\
\hline pBBohrR & pBBRI-MCS2 ohrR ${ }^{+}$ & This study \\
\hline pE1541 & pBBRI-MCS2 ohr::lacz & This study \\
\hline pETohrR & pET22b + ohr $^{+}$ & This study \\
\hline
\end{tabular}

\section{Disk diffusion assay}

Cells were grown in LB medium to an $\mathrm{OD}_{570 \mathrm{~nm}}$ of 0.4 . $0.5 \mathrm{ml}$ of cell suspension were mixed with $3 \mathrm{ml}$ of soft agar $(0.4 \%)$ and poured onto LB agar plates $(20 \mathrm{ml}) .10$ $\mu \mathrm{l}$ of $0.1 \mathrm{M}$ cumene hydroperoxyde $(\mathrm{CuOOH}), 0.5 \mathrm{M} \mathrm{t}$ butyl hydroperoxide (tBOOH), $10 \mathrm{M} \mathrm{H}_{2} \mathrm{O}_{2}$ or $50 \mathrm{mM}$ menadione were loaded on $8 \mathrm{~mm}$ paper disks placed on top agar. Plates were incubated for $24 \mathrm{~h}$ at $30^{\circ} \mathrm{C}$ and the clear zone was measured. $\mathrm{CuOOH}, \mathrm{tBOOH}$ and menadione solutions were made in $95 \%$ ethanol. $10 \mu \mathrm{l}$ of ethanol produced no growth inhibition in this assay.

\section{Construction of a $\Delta$ ohrR strain}

A 2,152 bp DNA fragment corresponding to the upstream region of ohrR was amplified on S. meliloti chromosomal DNA using the primers (GATCGGCCTCGACCCATACG) and (CCTCGTCTAGATGTCAT TGTCG; introduces an $\mathrm{XbaI}$ restriction site in place of ohrR ATG initiation codon) and cloned in pGEMTeasy vector (Promega, La Jolla, CA) giving pD3083. A 1,468 bp DNA fragment corresponding to the downstream region of ohrR was amplified using the primers (AGCTCTAGAGCACCTGCAG; introduces an XbaI restriction site in place of ohrR stop codon) and (CAGCGCGTGTGGCGGCG). This amplicon was digested with $X b a \mathrm{I}$ and $N s i$ (genuine site) and cloned into pK18mobsacB vector [51] between the $X b a \mathrm{I}$ and Pst I sites, giving pD3001. pD3083 and pD3001 were linearised with $\mathrm{XbaI}$ and ligated in order to assemble $o h r R$-upstream and -downstream sequences. Then pGEMTeasy vector was deleted through an EcoRI digest, giving pD4116, and the GmR cassette of p34SGm [52] was inserted into the $\mathrm{XbaI}$ site, giving $\mathrm{pD} 4244$. This final construction carries the ohr-ohrR region where the $o h r R$ open reading frame is replaced by a $G m R$ cassette; it was introduced into S. meliloti Rm1021 strain by triparental mating and recombinants were selected for on MSY medium containing gentamycin and sucrose. Double crossing over recombinants were identified as neomycin sensitive strains and confirmed by PCR. The 
mutation was transduced into $S$. meliloti Rm1021 strain using ФM12 [53], yielding R6.48.

\section{Inactivation of ohr}

A $4 \mathrm{~kb}$ chromosomal DNA fragment containing ohr and ohrR genes was amplified by PCR using the primers (GATCGGCCTCGACCCATACG) and (CAGCGCGTGTGGCGGCG) and cloned into pGEMTeasy vector. The insert was recovered with EcoRI and transferred to the same site on pK 18 mobsacB vector. The ohr open reading frame was then inactivated by introducing into the unique NotI site the GmR cassette from pBBR1-MCS5 digested with NotI. The resulting plasmid pD8657 was introduced into Rm1021 strain and double crossing events were selected as before and confirmed by PCR. The mutation was transduced into Rm1021 strain using ФM12, yielding R8.39.

\section{Construction of an ohr::Gm ${ }^{\mathrm{R}}, \Delta \mathrm{ohr}$ strain}

pD4116 carries the entire ohr sequence and a deletion of $o h r R$. The ohr gene was disrupted by introducing in its unique Not I site the GmR resistance cassette from pBBR1-MCS5 recovered through a NotI digest. The resulting pD5333was conjugated into $\mathrm{Rm} 1021$ strain and double crossing overs were selected as previously described and confirmed by PCR. Transduction of the mutations into Rm1021strain yielded R7.15.

\section{Construction of ohr::lacZ, ohrR::uidA into a wild type genetic background}

The $4 \mathrm{~kb}$ chromosomal fragment amplified for ohr inactivation contains two SalI sites near the 3'end of ohr and ohrR genes respectively. It was cleaved with SalI and the 980 bp DNA fragment containing the 5' regions of ohr and $o h r R$ was introduced into the XhoI site of pTH1705 vector (not replicative in $S$. meliloti) [54]. In the resulting pD5455 plasmid two transcriptional fusions are generated: ohr::lacZ and ohrR::uidA. pD5455 was introduced into Rm1021 strain by triparental mating. Single crossing over events were selected as GmR strains. Recombination was confirmed by PCR. The transduction of the mutation into Rm1021 strain yielded R7.16.

\section{Analysis of ohr regulation by OhrR}

ohr::lacZ region was released from pD5455 using $\mathrm{XbaI}$ and $S p h I$ and introduced between the corresponding sites of pBBR1-MCS2 vector (replicative in S. meliloti), yielding pE1541. This plasmid was introduced by triparental mating into the wild type strain and ohrR mutant (R6.48) and $\beta$-galactosidase activities were assayed in both strains.

\section{Complementation plasmids}

The open reading frames of $o h r$ and $o h r R$ were amplified using the primers (GATCGGCCTCGACCC
ATACG) and (CCTCGTCTAGATGTCATTGTCG) for $o h r$ and (CGTCGATAAAGAAGCCTGTG) and (CAG CGCGTGTGGCGGCG) for ohrR. The amplicons were cloned into pGEMTeasy, released by EcoRI cleavage and introduced into the same site in pBBR1-MCS2 vector. The correct orientation allowing the expression of these genes under the control of lac promoter was selected. The corresponding plasmids pBBohr and pBBohrR were introduced into $\mathrm{Rm} 1021$ strain and the various mutants by triparental mating.

\section{Purification of OhrR protein}

The ohrR open reading frame was amplified by PCR using the primers (CGACAATGACATATGACGAGG) and (AGCTCTCGAGTCGACTACCG) and cloned in pGEMT. The insert was released as an NdeI-XhoI DNA fragment and introduced into the expression vector $\mathrm{pET} 22 \mathrm{~b}+$ (Novagen) giving $\mathrm{pET}$ ohrR where the ohrR ORF is fused to a 6his-tag at its 3' extremity. BL21(DE3) cells harbouring pETohrR were cultured in LB medium at $37^{\circ} \mathrm{C}$ until $\mathrm{OD}_{570 \mathrm{~nm}}$ of 0.8 ; isopropyl- $\beta$-D-galactopyranoside was then added to a final concentration of 1 $\mathrm{mM}$. The culture was grown for an additional $4 \mathrm{~h}$, and cells were harvested by centrifugation $(5,000 \times \mathrm{g}, 10$ min, $\left.4^{\circ} \mathrm{C}\right)$. Bacterial cells were washed in TE $(10 \mathrm{mM}$ Tris pH 6.8, 1 mM EDTA) and resuspended in the same buffer with $1 \mathrm{mM}$ phenylmethylsulfonyl fluoride. Cells were disrupted by three passages through a French press (1,200 PSI), and cell debris were removed by centrifugation at $4^{\circ} \mathrm{C}, 12,000 \times g$ for $30 \mathrm{~min}$. Proteins were loaded on a heparin column (GE heath care), followed by a wash (10 column volumes) with buffer A (25 mM Tris- $\mathrm{HCl} \mathrm{pH} 8,25 \mathrm{mM} \mathrm{NaCl}, 2 \mathrm{mM}$ EDTA, $1 \mathrm{mM}$ DTT). Elution was performed with the same buffer containing $0.5 \mathrm{M} \mathrm{NaCl}$. The eluted fractions were analysed by SDS-PAGE, and those containing OhrR were pooled and dialysed against buffer A.

\section{Gel mobility shift}

The intergenic region between $o h r$ and $o h r R$ was amplified by PCR using the primers (ATGATGTCATTGTCGCAAATTC) and (CATGACAGTCTC CTTCCTTGTG) as a 113 bp DNA fragment. Complementary oligonucleotides (Figure 4) were also used in gel mobility assay; they were annealed in $50 \mathrm{mM}$ Tris$\mathrm{HCl}$ pH8, $0.25 \mathrm{M} \mathrm{NaCl}, 1 \mathrm{mM}$ EDTA. DNA probes $(20$ pmoles) were incubated with OhrR protein (0 to 100 pmoles) in $20 \mu$ l binding buffer $(20 \mathrm{mM}$ Tris- $\mathrm{HCl}(\mathrm{pH}$ 8.0), $50 \mathrm{mM} \mathrm{KCl}, 1 \mathrm{mM}$ EDTA, $50 \mu \mathrm{M}$ bovine serum albumin) at room temperature for $10 \mathrm{~min}$. Binding mixture was run on $6 \%$ polyacrylamide gel in Tris-borate buffer. Gels were stained with SYBR gold (Molecular Probes) in $10 \mathrm{mM}$ TBE pH 8.0 buffer and revealed with a transilluminator at $312 \mathrm{~nm}$. To oxidize OhrR, organic 
peroxides were added to the binding buffer; reduction of the protein was performed with DTT.

\section{Plant assays}

Medicago sativa L. var. Europe (alfalfa) was used as host plant for testing nodulation of $S$. meliloti strains according to [55]. Surface-sterilized germinating seedlings were grown in test tubes on nitrogen-free medium. One week old plants were inoculated with $10^{9}$ cells of wild type and ohr mutant of S. meliloti. Plants were analysed after 5 to 9 weeks of growth.

$\beta$-galactosidase and $\beta$-glucuronidase detection in plants Nodules were fixed and stained as previously described [56] and observed by light microscopy.

\section{Authors' contributions}

CB performed mutants' construction, CF, MA and VD carried out experiments concerning their phenotype characterization. AT performed gel shift experiments. $\mathrm{AT}$ and $\mathrm{CB}$ discussed the results and elaborated the final version of manuscript. All authors read and approved the final version of the manuscript.

\section{Acknowledgements and funding}

We thank S. Georgeault, C. Monnier, M. Uguet and M.C. Savary for technical assistance and J. P. Besnard for English improvement. This work was supported by the CNRS and the Ministère de la Recherche.

Received: 17 December 2010 Accepted: 13 May 2011

Published: 13 May 2011

\section{References}

1. Fernandez-Aunion C, Hamouda TB, Iglesias-Guerra F, Argandona M, ReinaBueno M, Nieto JJ, Aouani ME, Vargas C: Biosynthesis of compatible solutes in rhizobial strains isolated from Phaseolus vulgaris nodules in Tunisian fields. BMC Microbiol 2010, 10:192.

2. Pauly N, Pucciariello C, Mandon K, Innocenti G, Jamet A, Baudouin E, Herouart D, Frendo P, Puppo A: Reactive oxygen and nitrogen species and glutathione: key players in the legume-Rhizobium symbiosis. J Exp Bot 2006, 57(8):1769-1776.

3. Vriezen JA, de Bruijn FJ, Nusslein K: Responses of rhizobia to desiccation in relation to osmotic stress, oxygen, and temperature. Appl Environ Microbiol 2007, 73(11):3451-3459.

4. Santos R, Herouart D, Sigaud S, Touati D, Puppo A: Oxidative burst in alfalfa-Sinorhizobium meliloti symbiotic interaction. Mol Plant Microbe Interact 2001, 14(1):86-89.

5. Bolwell GP: Role of active oxygen species and NO in plant defence responses. Curr Opin Plant Biol 1999, 2(4):287-294.

6. Gonzalez-Flecha B, Demple B: Metabolic sources of hydrogen peroxide in aerobically growing Escherichia coli. J Biol Chem 1995, 270:13681-13687.

7. Imlay JA: Pathways of oxidative damage. Annu Rev Microbiol 2003, 57:395-418.

8. Flechard M, Fontenelle C, Trautwetter A, Ermel G, Blanco C: Sinorhizobium meliloti orpE2 is necessary for $\mathrm{H}_{2} \mathrm{O}_{2}$ stress resistance during the stationary growth phase. FEMS Microbiol Lett 2009, 290(1):25-31.

9. Santos R, Herouart D, Puppo A, Touati D: Critical protective role of bacterial superoxide dismutase in rhizobium-legume symbiosis. Mol Microbiol 2000, 38(4):750-759.

10. Jamet A, Sigaud S, Van de Sype G, Puppo A, Herouart D: Expression of the bacterial catalase genes during Sinorhizobium meliloti-Medicago sativa symbiosis and their crucial role during the infection process. Mol Plant Microbe Interact 2003, 16(3):217-225.

11. Barloy-Hubler F, Cheron A, Hellegouarch A, Galibert F: Smc01944, a secreted peroxidase induced by oxidative stresses in Sinorhizobium meliloti 1021. Microbiology 2004, 150(Pt 3):657-664.

12. Baker CJ, Orlandi EW: Active oxygen in plant pathogenesis. Annu Rev Phytopathol 1995, 33:299-321.

13. Jalloul A, Montillet JL, Assigbetse K, Agnel JP, Delannoy E, Triantaphylides C, Daniel JF, Marmey P, Geiger JP, Nicole M: Lipid peroxidation in cotton, Xanthomonas interactions and the role of lipoxygenases during the hypersensitive reaction. Plant I 2002, 32(1):1-12.

14. Halliwell B, Gutteridge JM: Oxygen toxicity, oxygen radicals, transition metals and disease. Biochem J 1984, 219(1):1-14.

15. Dubbs JM, Mongkolsuk S: Peroxiredoxins in bacterial antioxidant defense. Subcell Biochem 2007, 44:143-193.

16. Rhee SG, Chae HZ, Kim K: Peroxiredoxins: a historical overview and speculative preview of novel mechanisms and emerging concepts in cell signaling. Free Radic Biol Med 2005, 38(12):1543-1552.

17. Niimura Y, Poole LB, Massey V: Amphibacillus xylanus NADH oxidase and Salmonella typhimurium alkyl-hydroperoxide reductase flavoprotein components show extremely high scavenging activity for both alkyl hydroperoxide and hydrogen peroxide in the presence of $S$. typhimurium alkyl-hydroperoxide reductase 22-kDa protein component. J Biol Chem 1995, 270(43):25645-25650.

18. Poole LB: Bacterial defenses against oxidants: mechanistic features of cysteine-based peroxidases and their flavoprotein reductases. Arch Biochem Biophys 2005, 433(1):240-254.

19. Atichartpongkul S, Loprasert S, Vattanaviboon P, Whangsuk W, Helmann JD, Mongkolsuk S: Bacterial Ohr and OsmC paralogues define two protein families with distinct functions and patterns of expression. Microbiology 2001, 147(Pt 7):1775-1782.

20. Mongkolsuk S, Praituan W, Loprasert S, Fuangthong M, Chamnongpol S: Identification and characterization of a new organic hydroperoxide resistance (ohr) gene with a novel pattern of oxidative stress regulation from Xanthomonas campestris pv. phaseoli. J Bacteriol 1998, 180(10):2636-2643.

21. Gutierrez C, Devedjian JC: Osmotic induction of gene osmC expression in Escherichia coli K12. J Mol Biol 1991, 220(4):959-973.

22. Cussiol JR, Alves SV, de Oliveira MA, Netto LE: Organic hydroperoxide resistance gene encodes a thiol-dependent peroxidase. J Biol Chem 2003, 278(13):11570-11578.

23. Lesniak J, Barton WA, Nikolov DB: Structural and functional features of the Escherichia coli hydroperoxide resistance protein OsmC. Protein Sci 2003, 12(12):2838-2843.

24. Lesniak J, Barton WA, Nikolov DB: Structural and functional characterization of the Pseudomonas hydroperoxide resistance protein Ohr. EMBO J 2002, 21(24):6649-6659.

25. Rehse PH, Ohshima N, Nodake Y, Tahirov TH: Crystallographic structure and biochemical analysis of the Thermus thermophilus osmotically inducible protein C. J Mol Biol 2004, 338(5):959-968.

26. Hong M, Fuangthong M, Helmann JD, Brennan RG: Structure of an OhrRohrA operator complex reveals the DNA binding mechanism of the MarR family. Mol Cell 2005, 20(1):131-141.

27. Newberry KJ, Fuangthong M, Panmanee W, Mongkolsuk S, Brennan RG Structural mechanism of organic hydroperoxide induction of the transcription regulator OhrR. Mol Cell 2007, 28(4):652-664.

28. Fuangthong M, Helmann JD: The OhrR repressor senses organic hydroperoxides by reversible formation of a cysteine-sulfenic acid derivative. Proc Natl Acad Sci USA 2002, 99(10):6690-6695.

29. Eiamphungporn W, Soonsanga S, Lee JW, Helmann JD: Oxidation of a single active site suffices for the functional inactivation of the dimeric Bacillus subtilis OhrR repressor in vitro. Nucleic Acids Res 2009, 37(4):1174-1181.

30. Panmanee $W$, Vattanaviboon P, Poole LB, Mongkolsuk S: Novel organic hydroperoxide-sensing and responding mechanisms for OhrR, a major bacterial sensor and regulator of organic hydroperoxide stress. J Bacteriol 2006, 188(4):1389-1395.

31. Chuchue T, Tanboon W, Prapagdee B, Dubbs JM, Vattanaviboon P, Mongkolsuk S: ohrR and ohr are the primary sensor/regulator and protective genes against organic hydroperoxide stress in Agrobacterium tumefaciens. J Bacteriol 2006, 188(3):842-851. 
32. Mostertz J, Scharf C, Hecker M, Homuth G: Transcriptome and proteome analysis of Bacillus subtilis gene expression in response to superoxide and peroxide stress. Microbiology 2004, 150(Pt 2):497-512.

33. Ochsner UA, Hassett DJ, Vasil ML: Genetic and physiological characterization of ohr, encoding a protein involved in organic hydroperoxide resistance in Pseudomonas aeruginosa. J Bacteriol 2001 183(2):773-778.

34. Oh SY, Shin JH, Roe JH: Dual role of OhrR as a repressor and an activator in response to organic hydroperoxides in Streptomyces coelicolor. J Bacteriol 2007, 189(17):6284-6292.

35. Atichartpongkul S, Fuangthong M, Vattanaviboon P, Mongkolsuk S: Analyses of regulatory mechanism and physiological roles of Pseudomonas aeruginosa OhrR, a transcription regulator and a sensor of organic hydroperoxides. J Bacteriol 2010, 192:2093-2101.

36. Fuangthong M, Atichartpongkul S, Mongkolsuk S, Helmann JD: OhrR is a repressor of ohrA, a key organic hydroperoxide resistance determinant in Bacillus subtilis. J Bacteriol 2001, 183(14):4134-4141.

37. Sukchawalit R, Loprasert S, Atichartpongkul S, Mongkolsuk S: Complex regulation of the organic hydroperoxide resistance gene (ohr) from Xanthomonas involves $\mathrm{OhrR}$, a novel organic peroxide-inducible negative regulator, and posttranscriptional modifications. J Bacteriol 2001, 183(15):4405-4412.

38. Ramu SK, Peng HM, Cook DR: Nod factor induction of reactive oxygen species production is correlated with expression of the early nodulin gene rip1 in Medicago truncatula. Mol Plant Microbe Interact 2002, 15(6):522-528.

39. Djordjevic MA: Sinorhizobium meliloti metabolism in the root nodule: a proteomic perspective. Proteomics 2004, 4(7):1859-1872.

40. Klomsiri C, Panmanee W, Dharmsthiti S, Vattanaviboon P, Mongkolsuk S: Novel roles of ohrR-ohr in Xanthomonas sensing, metabolism, and physiological adaptive response to lipid hydroperoxide. J Bacteriol 2005, 187(9):3277-3281.

41. Vattanaviboon P, Whangsuk W, Panmanee W, Klomsiri C, Dharmsthiti S, Mongkolsuk S: Evaluation of the roles that alkyl hydroperoxide reductase and Ohr play in organic peroxide-induced gene expression and protection against organic peroxides in Xanthomonas campestris. Biochem Biophys Res Commun 2002, 299(2):177-182.

42. Soonsanga S, Lee JW, Helmann JD: Oxidant-dependent switching between reversible and sacrificial oxidation pathways for Bacillus subtilis OhrR. Mol Microbiol 2008, 68(4):978-986.

43. Soonsanga S, Lee JW, Helmann JD: Conversion of Bacillus subtilis OhrR from a 1-Cys to a 2-Cys peroxide sensor. J Bacteriol 2008, 190(17):5738-5745.

44. Palma M, DeLuca D, Worgall S, Quadri LE: Transcriptome analysis of the response of Pseudomonas aeruginosa to hydrogen peroxide. J Bacteriol 2004, 186(1):248-252.

45. Nanda AK, Andrio E, Marino D, Pauly N, Dunand C: Reactive oxygen species during plant-microorganism early interactions. J Integr Plant Biol 2010, 52(2):195-204.

46. Rubio MC, James EK, Clemente MR, Bucciarelli B, Fedorova M, Vance CP, Becana M: Localization of superoxide dismutases and hydrogen peroxide in legume root nodules. Mol Plant Microbe Interact 2004, 17(12):1294-1305.

47. Miller JH: Experiments in molecular genetics. Cold Spring Harbor Laboratory, Cold Spring Harbor, NY 1972.

48. Gouffi K, Pichereau V, Rolland JP, Thomas D, Bernard T, Blanco C: Sucrose is a nonaccumulated osmoprotectant in Sinorhizobium meliloti. J Bacteriol 1998, 180(19):5044-5051.

49. Sambrook J, Fritsch EF, Maniatis T: Molecular cloning: a laboratory manual. Edited by: Cold Spring Harbor. New York: Cold Spring Harbor; , 2 1989:

50. Bardonnet N, Blanco C: uidA antibiotic resistance cassettes for insertion mutagenesis, gene fusion and genetic constructions. FEMS Microbiol Lett 1992, 93:243-248.

51. Schafer A, Tauch A, Jager W, Kalinowski J, Thierbach G, Puhler A: Small mobilizable multi-purpose cloning vectors derived from the Escherichia coli plasmids pK18 and pK19: selection of defined deletions in the chromosome of Corynebacterium glutamicum. Gene 1994, 145(1):69-73.

52. Dennis JJ, Zylstra GJ: Plasposons: modular self-cloning minitransposon derivatives for rapid genetic analysis of gram-negative bacterial genomes. Appl Environ Microbiol 1998, 64(7):2710-2715.

53. Finan TM, Hartweig E, LeMieux K, Bergman K, Walker GC, Signer ER: General transduction in Rhizobium meliloti. J Bacteriol 1984, 159(1):120-124.
54. Cowie A, Cheng J, Sibley CD, Fong Y, Zaheer R, Patten CL, Morton RM, Golding GB, Finan TM: An integrated approach to functional genomics: construction of a novel reporter gene fusion library for Sinorhizobium meliloti. Appl Environ Microbiol 2006, 72(11):7156-7167.

55. Leigh JA, Signer ER, Walker GC: Exopolysaccharide-deficient mutants of Rhizobium meliloti that form ineffective nodules. Proc Natl Acad Sci USA 1985, 82(18):6231-6235.

56. Boivin C, Camut S, Malpica CA, Truchet G, Rosenberg C: Rhizobium meliloti Genes Encoding Catabolism of Trigonelline Are Induced under Symbiotic Conditions. Plant Cell 1990, 2(12):1157-1170.

57. Hanahan D: Studies on transformation of Escherichia coli with plasmids. Mol Biol 1983, 166(4):557-580

58. Finan TM, Hirsch AM, Leigh JA, Johansen E, Kuldau GA, Deegan S, Walker GC, Signer ER: Symbiotic mutants of Rhizobium meliloti that uncouple plant from bacterial differentiation. Cell 1985, 40(4):869-877.

59. Studier FW, Moffatt BA: Use of bacteriophage T7 RNA polymerase to direct selective high-level expression of cloned genes. J Mol Biol 1986, 189(1):113-130.

60. Meade HM, Long SR, Ruvkun GB, Brown SE, Ausubel FM: Physical and genetic characterization of symbiotic and auxotrophic mutants of Rhizobium meliloti induced by transposon Tn5 mutagenesis. J Bacteriol 1982, 149(1):114-122.

61. Kovach ME, Elzer PH, Hill DS, Robertson GT, Farris MA, Roop RM Peterson KM: Four new derivatives of the broad-host-range cloning vector pBBR1MCS, carrying different antibiotic-resistance cassettes. Gene 1995, 166(1):175-176.

doi:10.1186/1471-2180-11-100

Cite this article as: Fontenelle et al:: Resistance to organic hydroperoxides requires ohr and ohrR genes in Sinorhizobium meliloti. BMC Microbiology 2011 11:100.

\section{Submit your next manuscript to BioMed Central and take full advantage of:}

- Convenient online submission

- Thorough peer review

- No space constraints or color figure charges

- Immediate publication on acceptance

- Inclusion in PubMed, CAS, Scopus and Google Scholar

- Research which is freely available for redistribution

Submit your manuscript at www.biomedcentral.com/submit
C Biomed Central 